\title{
Numerical Simulation of Floating Pontoon Breakwater with ANSYS AQWA Software and Validation of the Results with Laboratory Data
}

\author{
Seyed Reza SAmAeI ${ }^{1}$, Farhood AzArsina ${ }^{2}$, Mohammad Asadian GHAHFEROKHI ${ }^{2}$ \\ ${ }^{1}$ Master of Engineering in Civil Engineering - Marine Structures, Faculty of Marine Science and \\ Technology (FMST), Science and Research Branch, Islamic Azad University, Tehran, \\ Iran. Seyedreza.samaei@yahoo.com \\ ${ }^{2}$ Assistant professor, Faculty of Marine Science and Technology (FMST), Science and Research \\ Branch, Islamic Azad University, Tehran, Iran. F.Azarsina@srbiau.ac.ir; Asadian@srbiau.ac.ir .
}

\begin{abstract}
The application of engineering software's to design and analyze civil infrastructures is increasing. In this regard, computational fluid dynamics software's used for the examination of the interaction of coastal and marine structures with waves play a unique role in the implementation of marine projects, since the operating costs of sea is significantly higher than that of land. In the present study, two models of floating pontoon breakwaters (i.e. simple pontoon as the first model and step pontoon as the second model) have been simulated with the application of ANSYS AQWA software. The main indicator of breakwater performance is the wave transmission coefficient (i.e. the ratio of the wave height on the back of the breakwater to the wave height entering the coastal zone) which is examined with the consideration of the changes occurring in the physical parameters such as draft, period, and amplitude of waves. The software solves the wave-structure interaction problem with the application of the boundary element method based on Laplace equation and presents water level meter as the output. Finally, the numerical results and the output of the software have been compared with the laboratory results to pursue the verification purpose. Laboratory data were extracted by the same team of researchers at Science and Research branch of Islamic Azad University. Furthermore, the obtained errors and deviations as well as the best possible performance and status of breakwaters at different waves have been specified.
\end{abstract}

Keywords: ANSYS AQWA software, floating pontoon breakwater, laboratory validation, marine structures, numerical simulation. 


\section{Introduction}

Creating a safe environment at beaches to prevent shoreline erosion, berthing of vessels in the ports, and their stevedoring have always received due attention in this field. One of the most significant structures built to create stilling basins in the harbors to cover safe arrival of ships to waterways and ports are breakwaters. Breakwaters dissipate the wave energy and reduce their height with creation of a barrier against the waves. In doing so, a tranquil environment is provided in the coast-facing section of the breakwaters. Furthermore, the possibility of constructing and utilizing coastal structures as well as performing shipping activities is facilitated. Breakwaters are built in various types and in general can be divided into two categories of fixed and floating ones.

The high costs and approximately long implementation time of fixed breakwaters in comparison with floating breakwaters can be considered as the main disadvantage leading to increased interest in the utilization of floating breakwaters over recent years. In addition, construction of fixed breakwaters is not feasible in all regions. In the construction site of fixed breakwaters, seabed should have the potential of foundation implementation. However, floating breakwaters can be implemented even in a condition in which the seabed soil does not have a high resistance. It must be mentioned that this type of breakwaters must be connected to the seabed with the utilization of a number of moorings; however, the pressure generated in the seabed soil in this case is much lower than that of the fixed breakwaters.

Gesraha et al. [1] in 2006 examined the performance of $\pi$-shaped floating breakwaters exposed to the waves with different angles of incidence with the application of numerical modeling method. In fact, their study addressed the possibility of increasing the efficiency of a rectangular floating breakwater by connecting a blade to its edge. In the mentioned study, not only conductivity but also the forces, mass, and damping coefficient of the structure were studied. They concluded that by increasing the blade height, the structure mass increases, damping coefficient reduces, and more energy dissipation occurs in front of the breakwater; all of which result in the reduction of transfer coefficient. Moreover, by increasing the angle of incident waves relative to the vertical position, transfer coefficient of the breakwater decreases.

Koutandos et al. [2] in 2011, following their previous research, examined the hydrodynamic characteristics of floating breakwaters with porous blades in a numerical study. They concluded that by increasing porosity of blades, transfer coefficient increases, as well. However, presence of porous blades in front of the breakwater is highly efficient in increasing energy dissipation of waves.

A number of studies have addressed the floating breakwaters in Iranian context, which are presented in the following section.

In a research conducted by Tamjidian and Ketabdari [3] in 2007, movement of the floating breakwater under impulsive breaking wave force was investigated. In this study, reaction of a 
floating breakwater against the breaking waves was analyzed using a two-dimensional model. The obtained results revealed that initial tension in moorings of the floating breakwaters had significant effect on their performance. Finally, the results of the numerical model were compared with laboratory results of Sannasiraj (1996), which indicated a favorable agreement between these two sets of results.

In a study conducted by Khalili and Shafiefar [4] in 2010, optimization of the floating pontoon breakwater geometry to increase its efficiency was examined. In this numerical study, first the efficacy of the floating pontoon breakwater with a cubic rectangular shape was dealt with. Furthermore, performance sensitivity of this breakwater with various values of draft, width of breakwater, and mooring system specifications as well as various specifications of waves such as wave height, wave period, and angle of the incident wave was examined. Moses software was used to evaluate the performance of floating pontoon breakwater. After conducting studies addressing floating pontoon breakwaters, optimization of the floating pontoon breakwater geometry to increase its efficiency was attended to. The purpose of optimization was to minimize the amount of wave passing through the breakwater. The optimization method used in this research was genetic algorithm.

This study consists of two parts: 1) Empirical studies and 2) numerical modeling and simulation. Moreover, the present study employed two models: 1) simple pontoon model and 2) step pontoon model. Initially, physical modeling was performed, and the two target models were made in the laboratory. Numerous tests were conducted in the wave flume of Sciences and Research branch of Islamic Azad University by the same team of researchers. The obtained results are presented in [5]. Then, according to the specifications of the physical model, computer modeling was done in CAD software, and the analysis of wave-structure interaction was simulated by the numerical software ANSYS/AQWA. Numerical and laboratory results and outputs were compared, and validation was carried out. Furthermore, the errors and deviations were calculated, and the best possible state and position were specified for different waves.

\section{Numerical Study}

In this study, to perform numerical examination of parameters affecting the transfer coefficient of the floating breakwater, ANSYS AQWA software, due to its comprehensiveness, was selected from among the available different software's used in marine engineering to model the flow around floating breakwaters. ANSYS AQWA software is one of the engineering analysis sections of ANSYS software, which can be used to examine the effects of wave, wind, and current on fixed and floating marine structures such as towboat, floating oil production platforms, semi-submersible structures, tension leg platforms, ships, renewable energy systems, and breakwaters. Current projects require effective structural design and analysis with the consideration of cost and time factors. Extensive modeling and analysis capabilities of the used software lead to the reduction of the overall costs and time of performing the project. 
Features of ANSYS AQWA software are not merely restricted to analysis of reflection and refraction effect of waves on structures or analysis of the controlled structures. This software is a powerful analytical tool for solving a good number of hydrodynamic problems. The following section offers a number of capabilities provided by this software. Structural movement analysis, determination of free height of structures, calculation of body membrane effects of fixed and floating objects in the marine environment, analysis of the interactions among several structures, dynamic analysis of the employed cables, calculation of the forces in various sections, analysis of tension leg platforms, calculation of trajectory of suspended objects, calculation and analysis of wave and wind systems, simulation of suspension among floating structures, discharge of boat from the main ship, analysis related to transmission of large structures from beach to offshore using barges or vessels, motion analysis of towing vessels are just a few of the capabilities offered by the mentioned software.

Generally, the capabilities of ANSYS AQWA software can be summarized in six sections:

- Analysis of the reflection and refraction of waves

- Initial static and dynamic stability including the effect of inhibitory and other physical connections

- Dynamic analysis of the frequency domain

- Time-domain analysis of irregular waves including their slow motion

- Non-linear time-domain analysis for regular or irregular waves of large amplitude

- Hydrodynamic load transfer for finite element analysis of structures

\section{Modeling of Floating Breakwater in ANSYS AQWA Software}

Modeling of the floating breakwater occurs in two stages: 1) drawing the model in Geometry section and (2) applying hydrodynamic conditions to the environment and structure as well as conducting hydrodynamic analysis in the Hydrodynamic Diffraction section.

Two techniques can be used to draw the target structure in ANSYS AQWA software. The first technique is to draw the structure in the AutoCAD software and then transfer it to ANSYS AQWA software. The second technique is to draw the structure in the Model Designer section of ANSYS AQWA software. The mentioned section provides the possibility of drawing various elements such as curved and non-curved panels and Morrison elements including Tube, Stub, and Disc. Figures 1 and 2 depict the drawn floating structure in the Model Designer section of ANSYS AQWA software. 


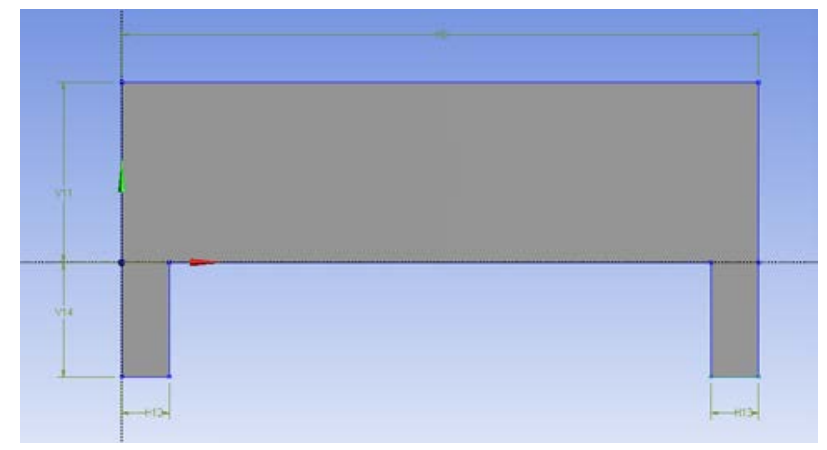

Figure1: Outline of a floating structure in the Model Designer section of ANSYS AQWA software

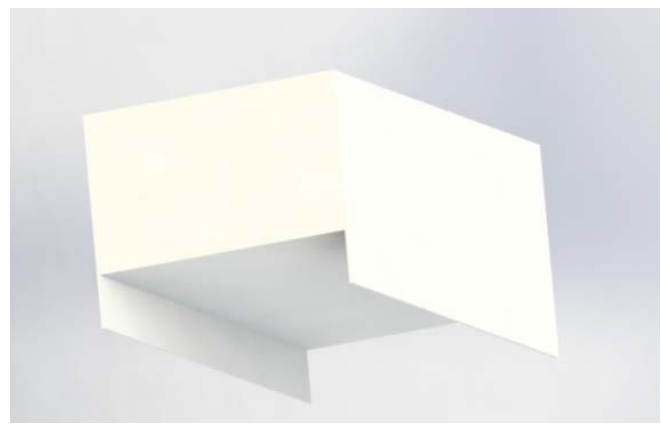

Figure 2: Three-dimensional view of floating breakwater model drawn in ANSYS AQWA software

ANSYS AQWA software is capable of analyzing the interaction between adjacent structures. Hence, the effects of movements of one structure on those of an adjacent structure are attended to in this software. These structures can be connected to each other with a pinned joint or cable or can be completely separate from each other. ANSYS AQWA software is capable of analyzing 50 joint structures. This capability provides the possibility of modeling the dynamic-mechanical and hydrodynamic configurations. In this type of modeling, joints can have stiffness.

In the Hydrodynamic Diffractions section, an integrated environment is provided to apply the fundamental hydrodynamic parameters required for the analysis of complex movements and responses of the structure. Furthermore, this section of the software offers a linear threedimensional reflection and refraction analysis of waves for multiple structures with perfect consideration of the interaction effects between the structures. Moreover, this section of the software can calculate the second-order forces for a wide range of water depths.

In the Hydrodynamic Diffractions section, hydrodynamic conditions such as water depth and density, frequency, height and direction of incident wave velocity, gravity, damping coefficient, added mass coefficient, drag coefficient, center of mass and buoyancy center of structure, structural sections' weight and moment of inertia, and meshing of structures and marine environment to the structure are applied. Design of regular waves can be performed in two forms 
of linear regular waves (Airy) and regular Stokes' waves of second-order. The present study made use of regular Airy waves.

One of the main points which worth considering in the numerical simulations is applying the boundary conditions. As the AQWA software is used to simulate the vessels in the sea, many of the boundary conditions are automatically applied by the software. The dynamics and kinematics boundary condition, seabed condition, and the boundary condition of the oscillating bodies can be considered as a number of these boundary conditions that are automatically applied to the structures. The most significant boundary condition that should be taken into account in the utilization of this software is specification of the underwater surface of the floating body. Two types of meshes are defined for modeling the floating structures. If some parts of the structure are below the water surface, square diffraction element will be defined. However, if some parts of the structure are above the water surface, square element will be specified. It must be mentioned that the elements defined above the water surface have no significant effect on the performance of floating breakwaters, and the software cannot calculate the exerted pressure on these specified elements. Specified elements should meet certain requirements to lead to better performance of the software. The maximum size of the used elements is specified according to the maximum frequency of the waves incidenting to the structure. The number of generated diffraction elements (below the water surface) should not be more than 18,000 elements because the software cannot solve the equations with more than 18,000 elements.

In modeling all the examined breakwaters in this study, the drag and added mass coefficients were considered to be equal to 1 . Fluid density was applied to be $1025 \mathrm{~kg}$ per square meter. With respect to the meshing procedure, the minimum and maximum meshing conditions were considered to be $0 / 75 \mathrm{~m}$ and $1 / 5 \mathrm{~m}$, respectively. Furthermore, two meters were used for meshing the marine environment. The method employed to determine the weight of floating breakwaters in the ANSYS AQWA software has been presented in Table 1.

Table 1: The method employed to determine the weight of floating breakwaters in the ANSYS AQWA software

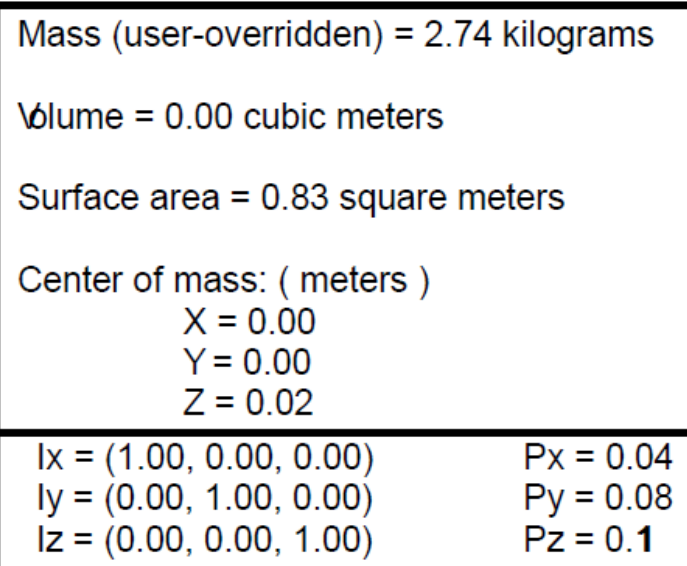


Figure 3 demonstrates the view of the completed floating pontoon breakwater model. It is worth mentioning that the effects of marine currents are not taken into account in the numerical modeling; hence, the obtained results cannot be valid in areas in which the effect of marine currents is remarkable.

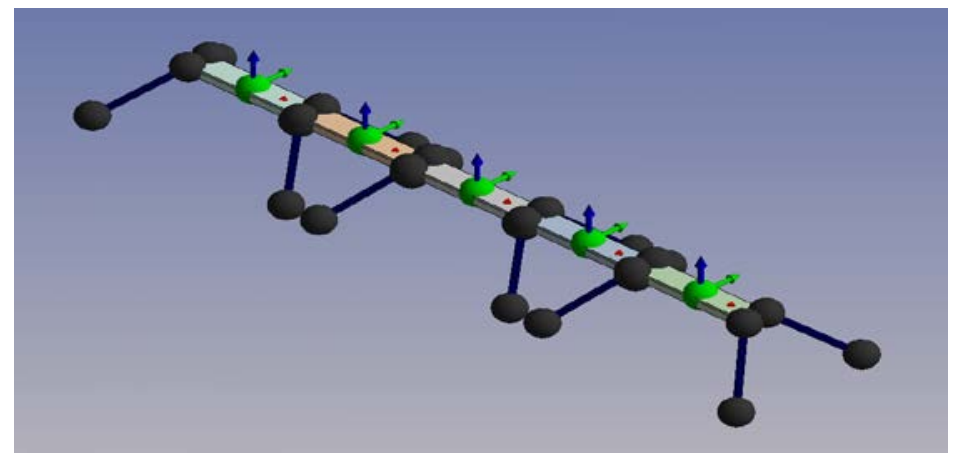

Figure 3: Completed floating pontoon breakwater model

Figures 4 and 5 present the meshing of simple and step pontoon models.

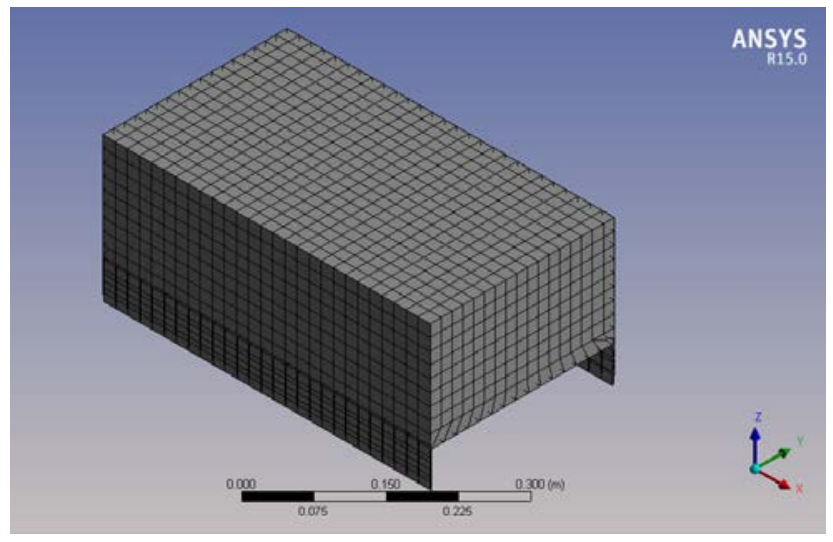

Figure 4: Meshing of simple pontoon breakwater

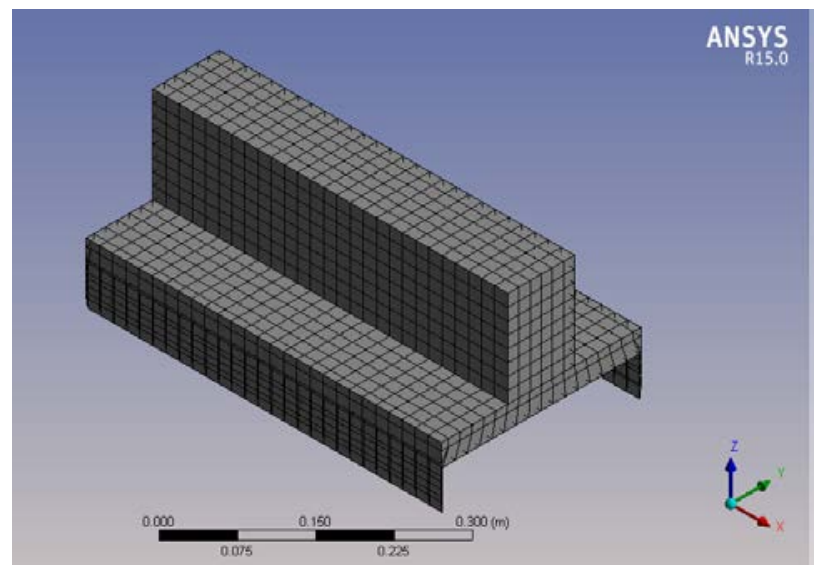

Figure 5:Meshing of step pontoon breakwater 


\section{Numerical and Laboratory Data of Simple and Step Pantones}

As already mentioned, simple and step pontoon breakwaters were examined by the same team of researchers in the wave flume of Sciences and Research branch of Islamic Azad University, and the obtained results are provided in [5] in detail. In this section, the main laboratory settings and outputs are concisely presented to remind the laboratory data and verify the numerical model.

First, pontoon breakwater model was located in the wave channel. The breakwater was moored by four elastic lines which were crossed and placed at the bottom of the wave channel using four one $\mathrm{kg}$ weights. Then, with the application of a paddle type wave-maker equipped with a controller, the mentioned breakwater was exposed to the effects of three types of waves with the following characteristics presented in Table 2. Wave channel had a wave absorption system at its end. The mentioned wave channel had 16 meters long, $50 \mathrm{~cm}$ width, and $80 \mathrm{~cm}$ height.

Table 2: Height and period of the wave

\begin{tabular}{|c|c|c|}
\hline Wave no. & $\mathrm{T}(\mathrm{s})$ & $\mathrm{A}(\mathrm{cm})$ \\
\hline 1 & 0.44 & 2.6 \\
\hline 2 & 0.68 & 2.4 \\
\hline 3 & 0.84 & 2.2 \\
\hline
\end{tabular}

Two sets of experiments, each consisting of nine tests, were conducted. The first set consisting of nine tests addressed the simple pontoon breakwater, and the second set consisting of nine tests examined the step pontoon breakwater. In each set of experiments, the effect of pontoon draft, wave height, and wavelength variables on the wave transmission coefficient were examined. The present conditions as well as the obtained results were video recorded by a high speed camera with technical specifications of MotionBlitz Cube 3 Mikrotron at 100 frames per second, and then the recorded films were converted to images. Test data are fully presented in [5].

The software outputs for wave level around the breakwater are provided in Figure 6. Finally, comparison of the numerical and laboratory results is presented in Table 4 and Figures $7-12$.

Table 4: Numerical results of transfer coefficient in different waves and drafts

\begin{tabular}{|c|c|c|c|c|c|c|}
\hline \multirow{2}{*}{$\begin{array}{c}\text { Draft (cm) } \\
\text { T }[\mathrm{s}]\end{array}$} & 7.3 & 7.8 & 8.3 & 7.3 & 7.8 & 8.3 \\
\hline 0.44 & 0.33 & 0.33 & 0.33 & 0.33 & 0.33 & 0.4 \\
\hline 0.68 & 0.5 & 0.4 & 0.4 & 0.43 & 0.2 & 0.75 \\
\hline 0.84 & 0.5 & 0.5 & 0.5 & 0.4 & 1.5 & 0.67 \\
\hline
\end{tabular}


Bulletin de la Société Royale des Sciences de Liège, Vol. 85, 2016, p. 1487 - 1499

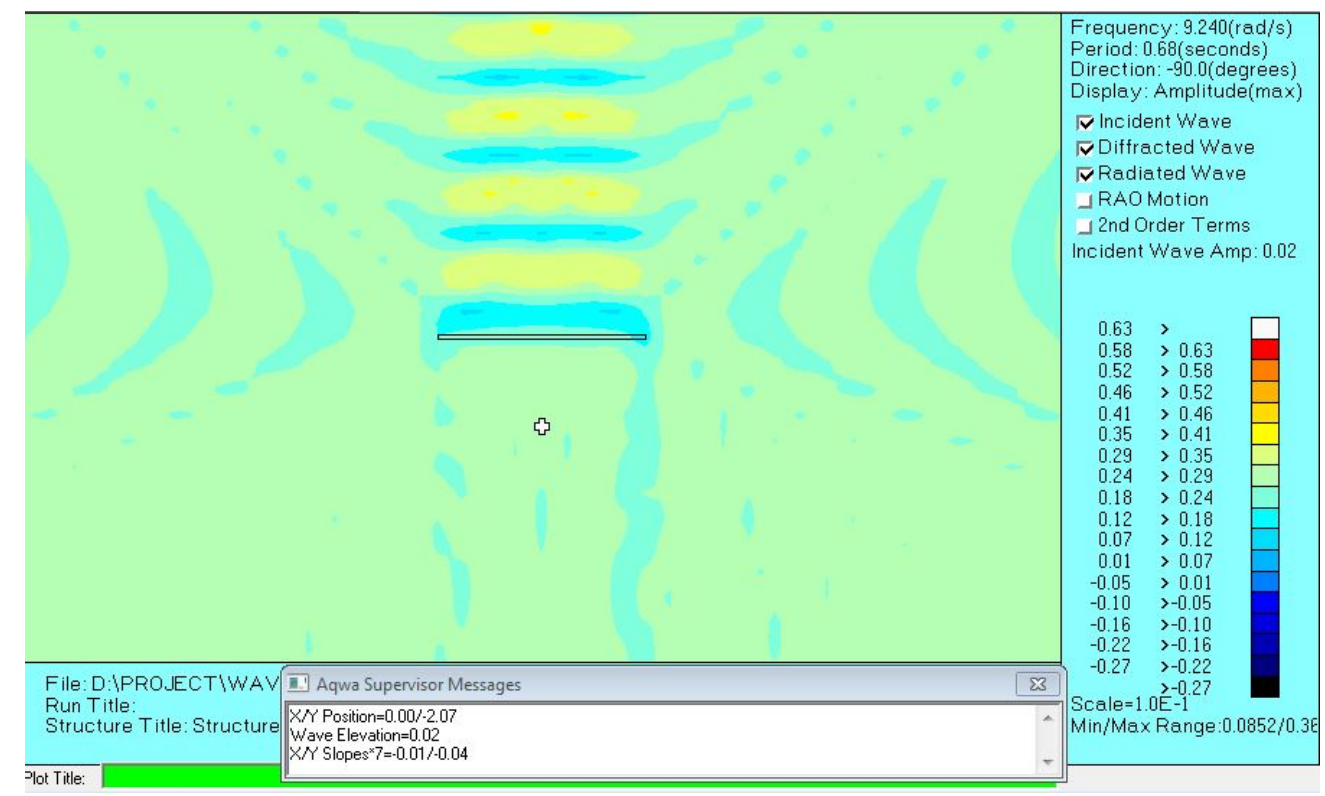

Figure 6: Wave level around the simple pontoon breakwater

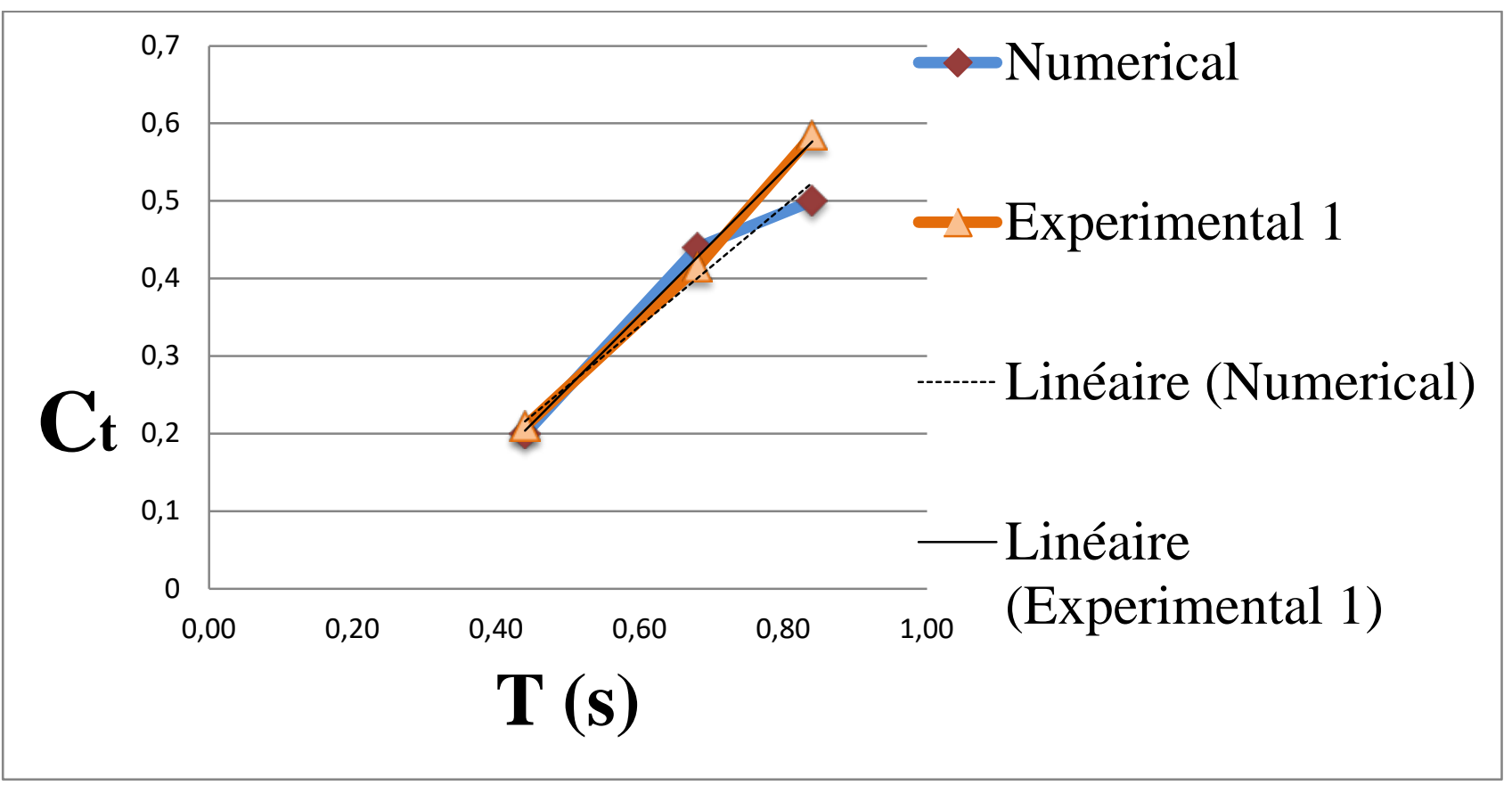

Figure7: The comparison of the numerical and laboratory results of transfer coefficients of a simple pontoon breakwater with a draft of $7 / 3 \mathrm{~cm}$ 
Bulletin de la Société Royale des Sciences de Liège, Vol. 85, 2016, p. 1487 - 1499

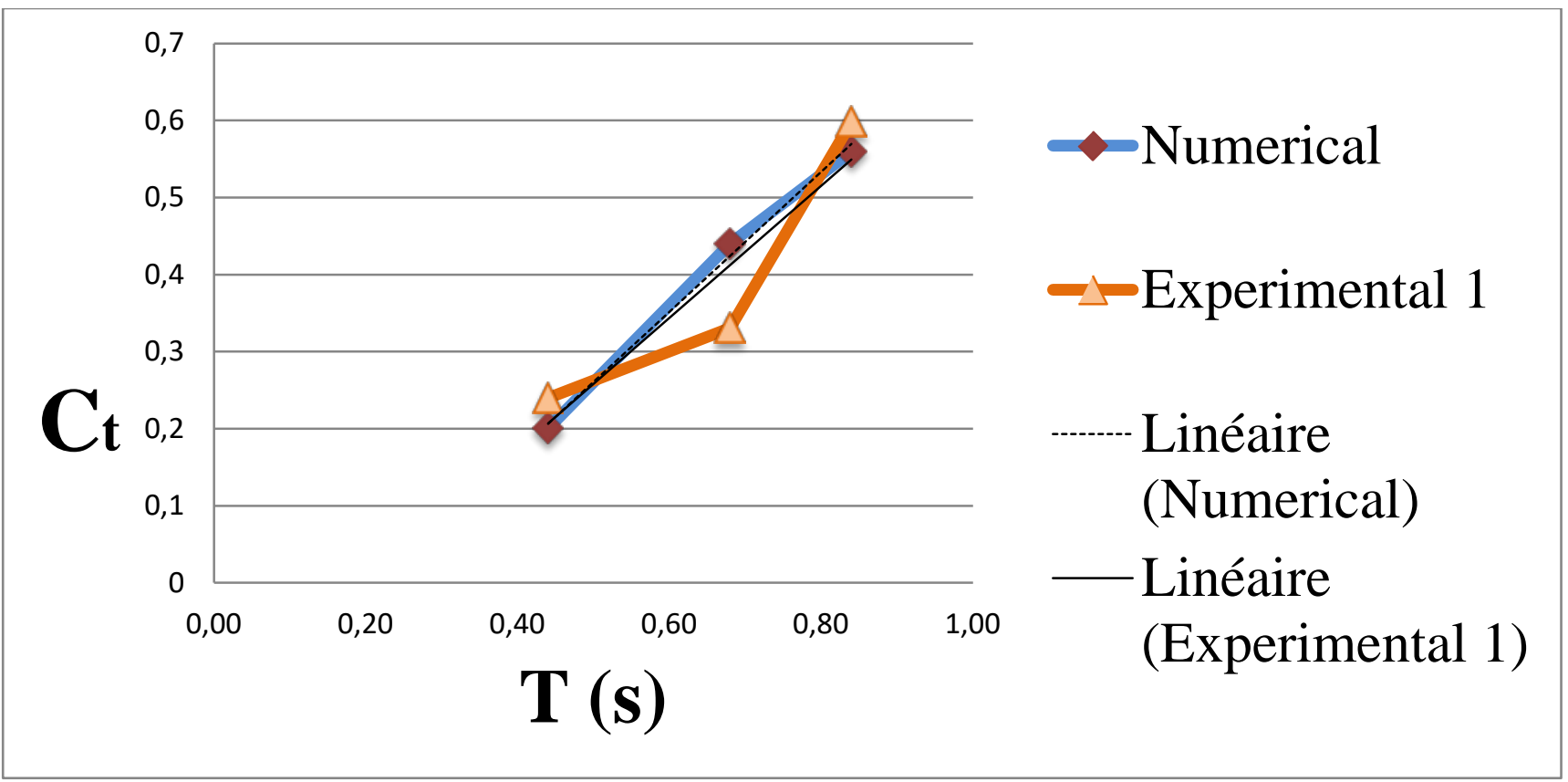

Figure 8: The comparison of the numerical and laboratory results of transfer coefficients of a simple pontoon breakwater with a draft of $7 / 8 \mathrm{~cm}$

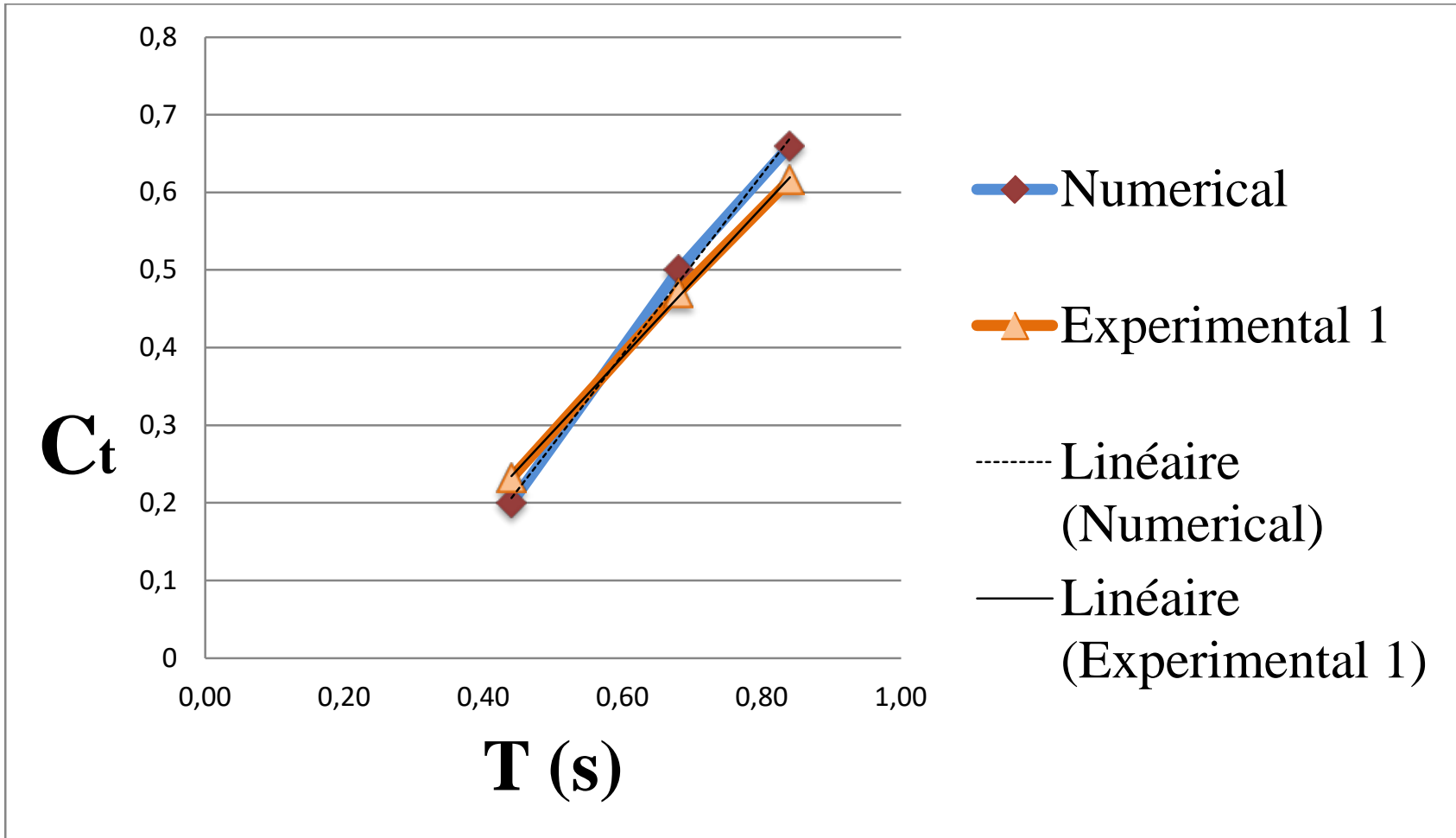

Figure 9: The comparison of the numerical and laboratory results of transfer coefficients of a simple pontoon breakwater with a draft of $8 / 6 \mathrm{~cm}$ 
Bulletin de la Société Royale des Sciences de Liège, Vol. 85, 2016, p. 1487 - 1499

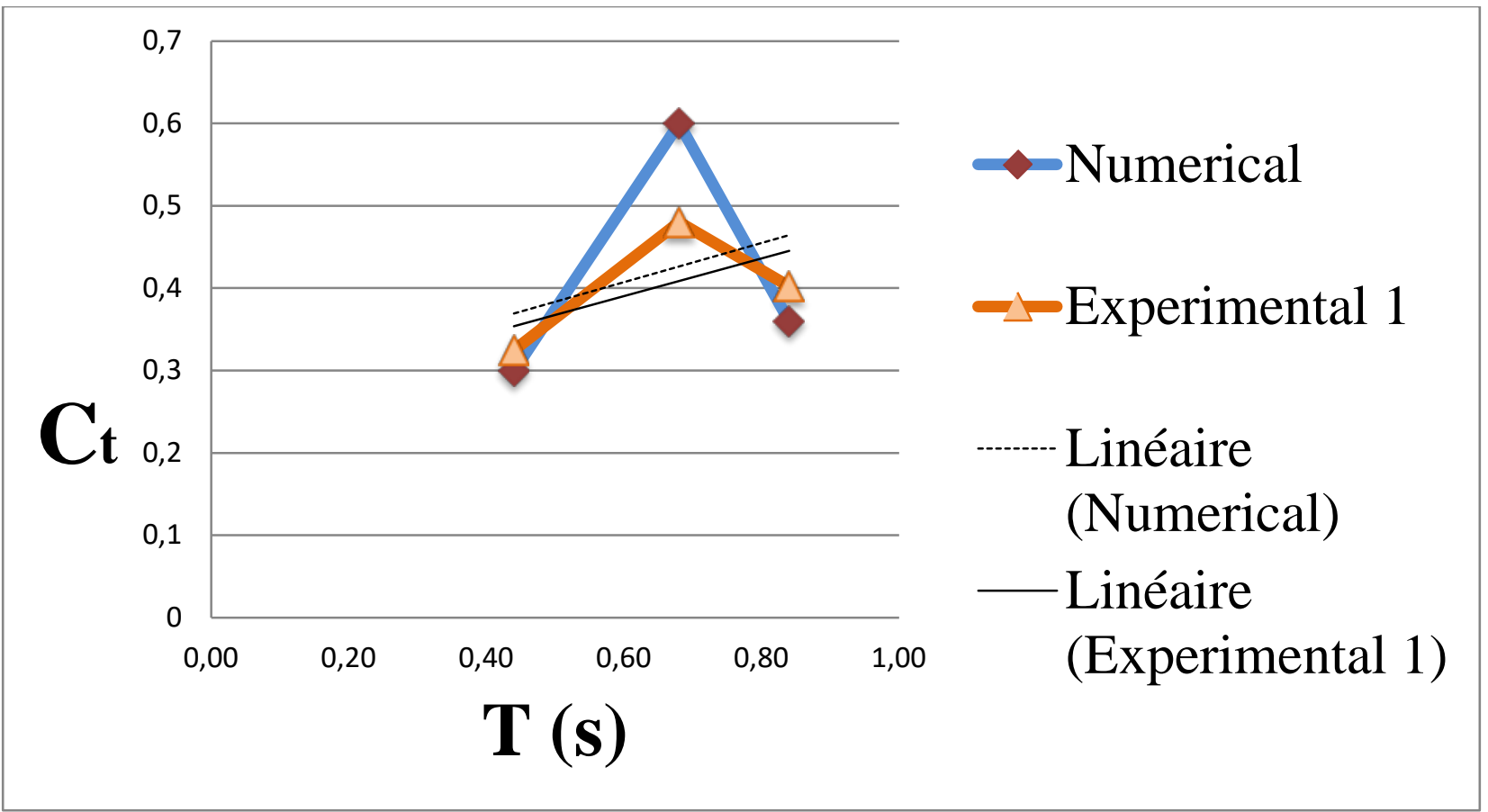

Figure10: The comparison of the numerical and laboratory results of transfer coefficients of a step pontoon breakwater with a draft of $7 / 3 \mathrm{~cm}$

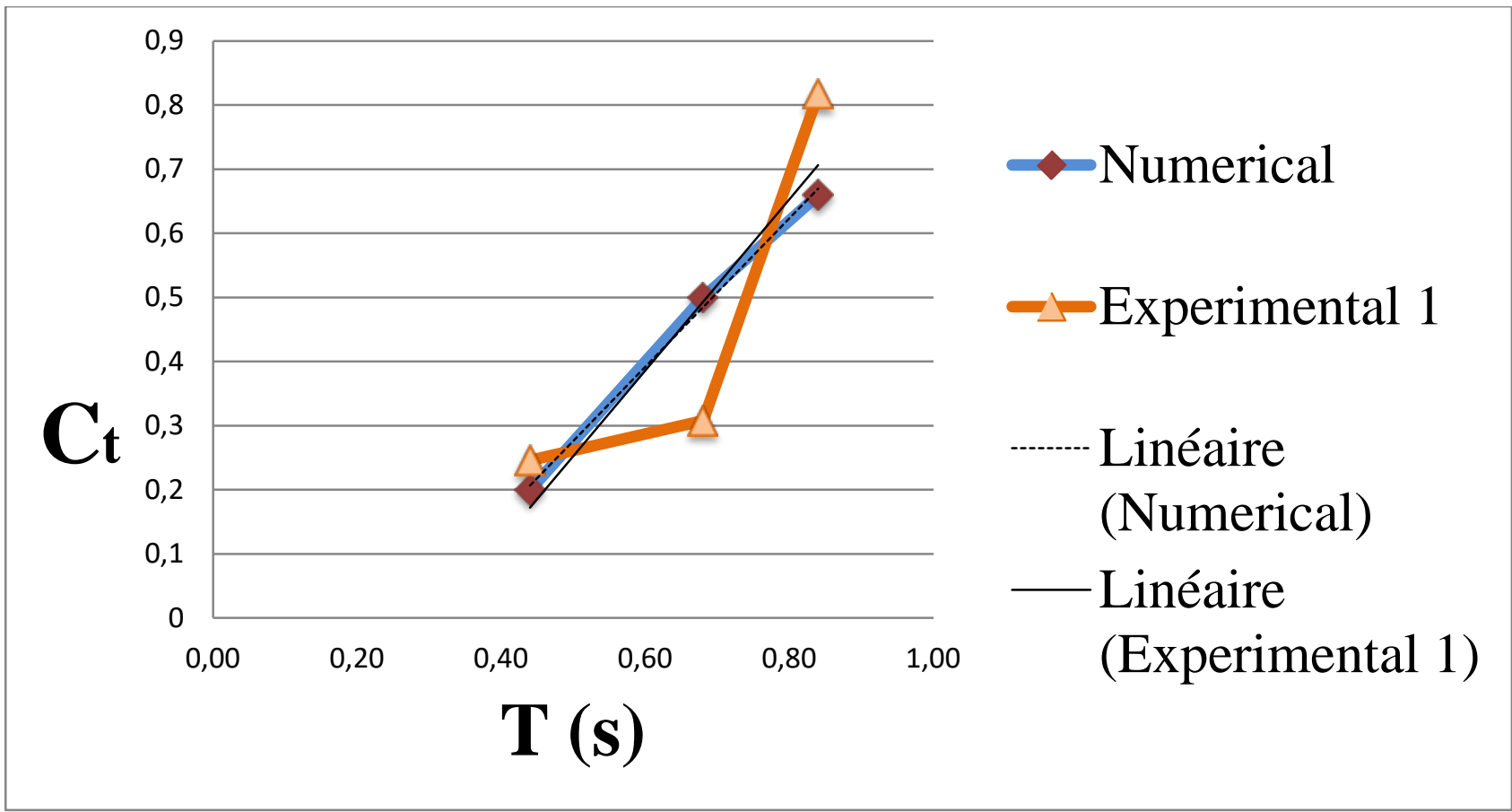

Figure11: The comparison of the numerical and laboratory results of transfer coefficients of a step pontoon breakwater with a draft of $7 / 8 \mathrm{~cm}$ 
Bulletin de la Société Royale des Sciences de Liège, Vol. 85, 2016, p. 1487 - 1499

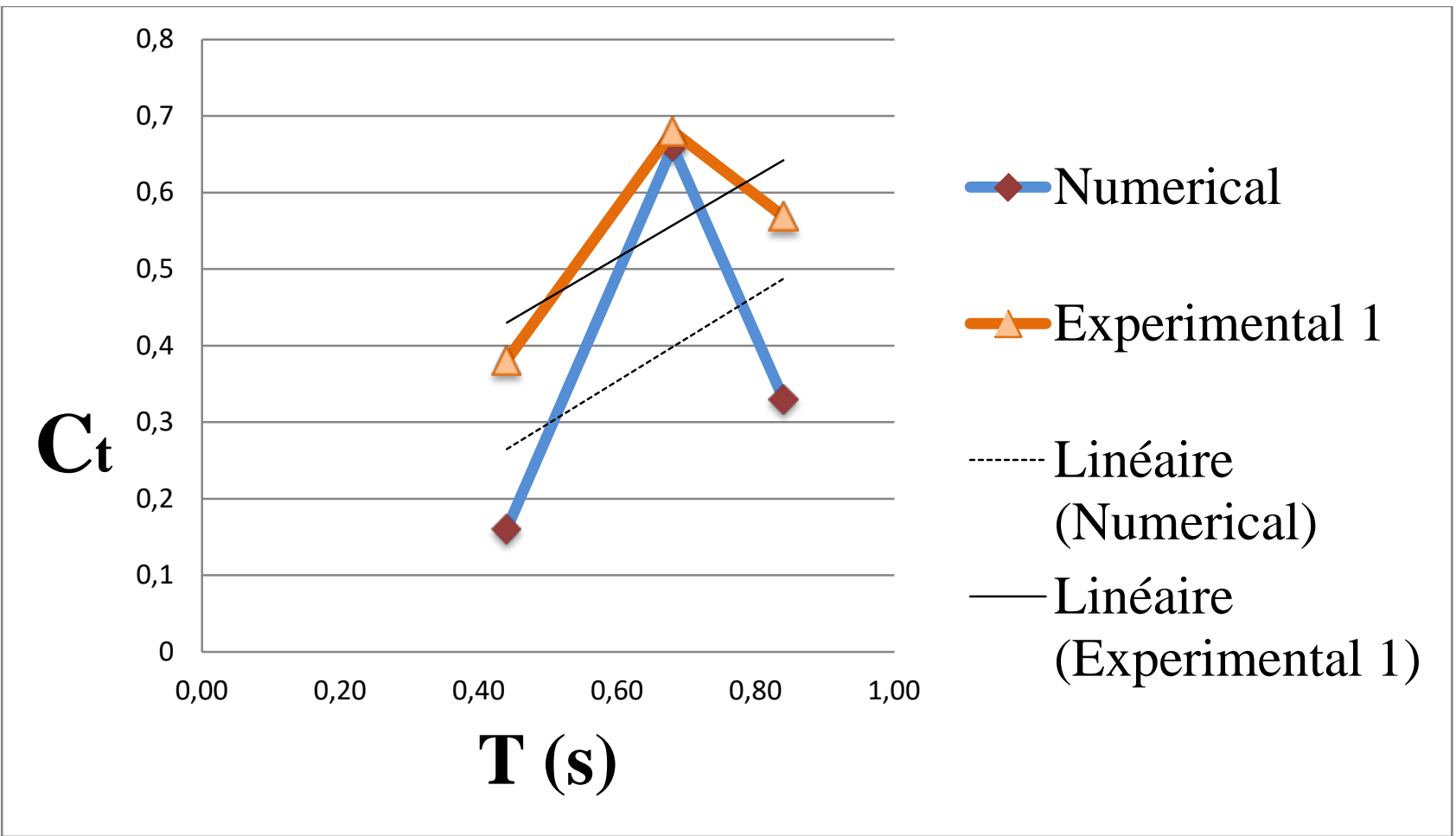

Figure12: The comparison of the numerical and laboratory results of transfer coefficients of a step pontoon breakwater with a draft of $8 / 6 \mathrm{~cm}$

\section{Conclusion}

The obtained results in this study can be summarized as follows:

- The possibility of achieving a numerical model that presented good consistency with the laboratory results.

- If the natural period of structures is equal to the period of waves, the breakwater loses its efficiency. Hence, it is recommended that researchers consider the mentioned point in designing the breakwaters.

- Any changes in the form of the breakwater resulting in an increase in the extinction coefficient or reflection could lead to the improvement of the breakwater efficiency.

- In the present study, the simple pontoon breakwater in a wave with a period of 0/44 seconds and in the draft level of 7/3 cm revealed the best performance. Furthermore, step pontoon breakwater presented the best performance for the wave with identical period and draft level of $7 / 8 \mathrm{~cm}$.

- In a wave with a period of $0 / 68$, both of the simple and step pontoon breakwaters in the draft of $7 / 8 \mathrm{~cm}$ revealed the best performance. 
- In a wave with a period of $0 / 84$, both of the simple and step pontoon breakwaters in the draft of $7 / 3 \mathrm{~cm}$ revealed the best performance.

\section{References}

1. Gesraha, M.R; "Analysis of P shaped floating breakwater in oblique waves: I. Impervious rigid wave boards”, Applied Ocean Research, Vol. 28, pp. 327-338, 2006.

2. Koutandos, E.V., Prinos, P.E; "Hydrodynamic characteristics of semi-immersed breakwater with an attached porous plate”, Ocean Engineering, Vol.38, pp. 34-48, 2011.

3. Tamjidian, A.R., Ketabdari, M.J., "Hydrodynamic analysis of floating breakwater due to sea waves” ICOPMAS 2006, Tehran, Iran, In Persian

4. Khalili, H., "Floating breakwater geometry optimization to increase efficiency" Master thesis, tarbiat modares university 2010, Tehran, Iran, In Persian

5. Samaei, S.R., Azarsina, F., Aasadian Ghahferokhi, M., "Introducing New Designs for Floating Breakwater: Simple Pontoon vs. Step Pontoon - Experimental Analysis of Coefficient of Transmit” The third international conference on recent innovations in civil engineering , architecture \& urban planning, September 16, 2016, Tehran, Iran, In Persian 